\title{
Reverse logistics of Indian E-Commerce Industry- Consumer Perspective and Ways to Improve
}

\author{
Avinash Kumar Pathak, Neeraj Joshi, Rajesh Kumar
}

\begin{abstract}
The modern supply chain has become complex and multi-locational, and efficient movement of material contributing to business success. The industry that deals with the movement of goods from one point to another is known as the logistics industry. Reverse logistic is a process of moving materials back from their consumer destination to their point of manufacturer or the distribution center in order to recapture their value for redistribution, or to dispose them properly. The movement of goods backwards in the supply chain is as important as the movement of goods forward in the supply chain. With the introduction of $e$ commerce and increase in the footprint of digitalization, the expectations of the consumers and the industries have reached an all-time high. We have used customer survey to know their perspective and then we have analyzed and visualized the data using Tableau. This research paper will focus on the Indian $e$ commerce industry and how end-consumers think differently than the industry, and how the gap in the quality of service is too wide between tier-1 cities and tier-2 or tier- 3 cities. We have used our data to analyze and find how can big data and blockchain help these industries in finding modern day solutions.

Keywords: Logistics, E-commerce, supply chain, big data analytics, blockchain, reverse logistics, secondary logistics
\end{abstract}

\section{INTRODUCTION}

India is the fifth-largest and fastest-growing trilliondollar economy in the world, with a nominal GDP of \$2.94 trillion (Caleb Silver, 2020). India has become the fifthlargest economy in 2019, overtaking the United Kingdom and France. Not only this, Indian government is targeting to make India a 5 trillion- dollar economy by 2025. But our focus is on the logistics industry and there too, in reverse logistics. As also mentioned in The Economic Times, "India's logistics industry had a valuation of USD 160 billion in 2018 and was estimated to touch USD 215 billion by 2020" (PTI, 2018). As quoted by Shivam Batham on a renowned website, "According to estimates, the market size for reverse logistics is approximately $\$ 30 \mathrm{bn}$ and is expected to reach $\$ 50$ bn by 2020, growing at a CAGR of $10 \%$ " (Shivam Batham, 2019). But one thing is pulling back the growth of e-commerce industry, and that is reverse logistics.

Revised Manuscript Received on August 13, 2020.

* Correspondence Author

Avinash Kumar Pathak*, Student, NMIMS, Mumbai, India. E-mail: mail.to.avi54@gmail.com

Neeraj Joshi, Student, NMIMS, Mumbai, India. E-mail: joshineerajdei@gmail.com

Rajesh Kumar, Professor, IFIM Bengaluru, India. E-mail: rajeshblue@gmail.com

(C) The Authors. Published by Blue Eyes Intelligence Engineering and Sciences Publication (BEIESP). This is an open access article under the CC BY-NC-ND license (http://creativecommons.org/licenses/by-nc-nd/4.0/)
With the increased attention of the government of India towards its logistics industry, it is the golden period from 2020 to 2025, when we can work towards bringing a mammoth change in the logistics industry.

The Government of India has set the target to bring down the current 14\% logistics cost of India's GDP to 9\% by 2022 and has requested the Ministries of Railways, Transport, Shipping and Aviation to work in tandem in order to reach the aforementioned goal (The Hindu Newspaper, 2019).

E-commerce is heavily reliant on logistics. India's ecommerce market is growing at an annual rate of $51 \%$ (Shivam Batham, 2019). Given the size of the industry, it is imperative for the industry to have highly efficient forward as well as reverse supply chains. According to (Khalid Saleh, 2016), 30\% of products sold on e-commerce platforms are returned as compared to $8.89 \%$ in brick and mortar stores. It is approximately one-third of the total items sold on e-commerce websites. With the increase in internet users to approximately $400 \mathrm{Mn}$, reverse logistics has suddenly become more relevant and noticeable due to realtime feedback and returns generated by end customers. While the retail segment penetration has sky-rocketed to 65 Mn users a month, reverse logistics is struggling to keep pace with the demand (Shivam Batham, 2019). As per Rogers and Tibben-Lembke, Reverse logistics ("RL") is defined as "The process of planning, implementing, and controlling the efficient, cost effective flow of raw materials, in-process inventory, finished goods and related information from the point of consumption to the point of origin for the purpose of recapturing value or proper disposal." (Rogers and Tibben-Lembke, 1999). With time, the definition of reverse logistics has also kept evolving. So, let us propose one recent definition of reverse logistics. Adlmaier and Sellitto (2007) suggests, "reverse logistics can be described as the field of organizational logistics aiming to manage, in an integrated way, all the logistic aspects of the return of goods to the productive cycle, through reverse distribution channels of post-selling and of postconsumption, aggregating their economic and environmental value. Reverse logistics studies the reverse distribution channels; i.e., channels that follow the opposite flow to the original chain of materials, aiming to aggregate value of the return by their reintegration to a point of the productive cycle of origin, or to another productive cycle, as input or raw material". 
The most formal definition of RL, which is given by the Reverse logistics executive council, is "a specialized segment of logistics focusing on the movement and the management of products and resources after the sale and after the delivery to the customer" (Fen Ma, 2010).

Now after we know what reverse logistics is, we need to find ways to improve its efficiency so that the modern-day e-commerce companies are able to improve the customer experience along with the reduction in pick-up turn-around time. Therefore, we are proposing the use of modern-day tools such as Blockchain and Big Data to counter the inefficiency in dealing with reverse logistics. Blockchain was firstly invented by Satoshi Nakamoto in 2008 as a cryptocurrency called "Bitcoin" (Meng and Qian ,2018). The Blockchain technology provides a novel approach to building trust in a trustless environment and thereby guarantees data integrity, availability, traceability, and security in data management (Meng and Qian ,2018). Cryptography is one the major tools of Blockchain to guarantee the data integrity and security. Basically, blockchain technology is a distributed database of records or shared public/private ledgers of all digital events that have been executed and shared among blockchain participating agents (Crosby et al., 2016). Going ahead with our study on reverse logistics, we found a research paper by Mauro, Greco and Grimaldi, where they mentioned, "Big Data is the information asset characterized by such a high volume, velocity and, variety to require specific technology and analytical methods for its transformation into value" (Mauro, Greco, and Grimaldi, 2016). BDA involves the use of advanced analytics technique to extract valuable knowledge from vast amount of data, facilitating data driven decision-making (Nguyen, ZHOU, Spiegler, Ieromonachou, and Lin, 2018, p.254-264). Big Data has been characterized by 5Vs: Volume, Variety, Velocity, Veracity and Value (Nguyen, ZHOU, Spiegler, Ieromonachou, and Lin, 2018, p.254-264). Volume refers to the magnitude of data which is increasing exponentially. Variety refers to the fact that any heterogeneous source can be the source of data, for examples, mobile phones, IoT devices, etc. Velocity refers to the speed of data generation and delivery. Veracity, stresses the importance of data quality and level of trust. Value refers to the process of revealing underexploited values from BD to support decision making (Nguyen, ZHOU, Spiegler, Ieromonachou, and Lin, 2018, p.254-264).

In this research paper, we had put forward a survey that will helped us to understand the problems faced by endconsumers, and finally, we have suggested few solutions to tackle the problem of delay in reverse pick-ups using blockchain and big data analytics.

\section{LITERATURE REVIEW}

Reverse logistics has been a challenge for all the companies throughout the world. Ever since the introduction of ecommerce websites, almost all the companies have focused on delivering goods faster but there are very few companies who have focused on the return part of it with equal weight. Since India is a growing e-commerce hub, it is time for all the companies to increase its consumer base by improving the service quality. In their study - Impact of E-commerce in India: Issues and Challenges - Nitika and Deepam, pointed out the reasons behind the growth of e- commerce in India. As per them, "These reasons were busy lifestyle, high disposable income, awareness of products, rising computer educational level and, increased usage of internet" (Nitika Goyal and Deepam Goyal, 2016). Now, there are a lot of consumers who have switched to e-commerce platforms from the traditional brick and mortar shops just because these platforms provide hassle-free returns and door-to-door deliveries and pick-ups. According to a study by Khalid Saleh, " $30 \%$ of all products ordered online are returned as compared to $8.89 \%$ in brick-and-mortar stores" (Khalid Saleh, 2016). This shows that returns play a very important role in consumer's purchase experience but this also takes us to one other point, and that is the scope of improvement in reverse logistics. We analyzed the study on E-commerce retail logistics in India by KPMG and found that electronics retail was the maximum e-commerce retail segment by value standing at $48 \%$, followed by apparel at $29 \%$. These 2 biggest e-commerce retail segments sum to more than $75 \%$ of the total sales in terms of value (KPMG, 2018). Ecommerce Product Return Rate - Statistics and Trends (Khalid Saleh, 2016) studied the impact of return policy on customers and found that " $92 \%$ of the consumers surveyed said that they will buy again if product return process is not cumbersome". Another, major finding of his survey was related to the reason of the return order placed by the consumer. (Prakash, Barua, and Pandya, 2015) studied the barriers analysis for reverse logistics implementation in Indian Electronics Industry using Fuzzy Analytic Hierarchy Process and has given the major reasons resulting into poor reverse logistics services in the Indian electronics industry and they are, Lack of coordination/ collaboration with 3PL providers, customers perception about RL, and lack of systems to monitor return. As per, (Agarwal, 2018), who studied Reverse Supply chain (RSC) Issues in Indian electronics industry, "In India, there is a lack of interest in the adaption of RSC and the product flow in RL are uncertain with respect to quantity, quality and timing of return". (Fen Ma, 2010) says that, "E-commerce companies should regard reverse logistics as a strategic activity to improve proper customer satisfaction and enhance supply chain competitiveness". She also says, E-commerce companies are awaked by severe pressure and fierce competition. Many of them have to review the role of reverse logistics in their strategic planning; and they are no longer to treat RL as an afterthought. (Schatteman, 2013), has suggested the four keys steps involved in a return process and they are: local screening, collection, sorting and disposition. In order to substantiate our literature review, we also studied research papers on Blockchain and BDA. As per (Deloitte, 2017), Blockchain enables the tracking and tracing of finished goods and material, providing users with a high level of trust that the data they view and store in the chain is correct and has not been altered by an unauthorized party. (Zhu and Kouhizadeh, 2019), in their research paper said, "Blockchain technology provides traceability, transparency, security, accuracy and smart execution, which can all contribute to the product deletion and rationalization decision". (Wu, Cao, Yang, Tung, Jiang, Tang, Liu, Wang, and Deng, 2019) has provided the insight of the potential opportunities to apply Blockchain technology in SCM.

Blue Eyes Intelligence Engineering \& Sciences Publication (C) Copyright: All rights reserved. 
(Rožman, Vrabič, Corn, Požrl, and Diaci, 2019) said that so far, an integration of Blockchain into the supply chain has been carried out with the transactions on self-executing smart contracts which can serve as a public database for tracking of the products.

In its white paper, (DHL, 2013) says, "The logistics sector is ideally placed to benefit from the technological and methodological advancements of Big Data". In the same paper, we read and analyzed that there consumer experience can be improved by implementing some innovative ways of big data analytics. These ideas were Real time route optimization, Crowd based pickup and delivery, strategic network planning, operational capacity planning, customer loyalty management, continuous service improvement \& product innovation and, risk evaluation \& resilience planning. All this can be achieved using big data analytics.

We studied the Deloitte's report on Blockchain and found that it enables the tracking and tracing of finished goods and material, providing users with a high level of trust that the data they view and store in the chain is correct and has not been altered by an unauthorized party (Deloitte, 2017). One more important aspect of blockchain is that it helps maintain transparency. Blockchain advocates claim transparency, speed, accessibility and non- falsifiability as the cornerstones of this new paradigm. Blockchain technology should make it much more difficult, if not impossible, for illicit or counterfeit products, for example, adulterated or non-compliant excipient, or goods whose processing is environmentally detrimental to enter legitimate supply chains. As quoted by Apte and Petrovsky, "It would enable end users to verify exactly how, where and by whom the product they intend to purchase has been assembled and made, thereby denying a market for illegal and counterfeit products" (Apte and Petrovsky, 2016).

Study of research paper on BDA, added another perspective to look at the solution of the problem which we are studying in this research paper. (Acharjya and Ahmed, 2016), said that the concept of IoT is becoming more pertinent to the realistic world due to the development of mobile devices, embedded and ubiquitous communication technologies, cloud computing and data analytics. (Nguyen, ZHOU, Spiegler, Ieromonachou, and Lin, 2018) suggests that the research on applying BDA on RL and closed-loop supply chain (CLSC) should be proactively taken. (Ma, Kwak, and Kim, 2014, p.189-199) said that the BDA that has already been applied in product lifecycle design and assessment would be useful in predicting product returns and estimating the return quality. After going through the literature available and the recent e-commerce policies of Indian government, we observed that reverse logistics is going to be one of the major factors in enhancing the productivity of e-commerce as well as logistics industry. But we found that there is a lot of work that needs to be done in this domain as the research that has been conducted till date is either too minimal/low or too obsolete. There was no work done to find out the average satisfaction rate of endconsumers and how many days does it take to arrange the pick-up of any item whose order is placed on the ecommerce platform. So, in this paper we have studied this time component of reverse logistics. We have also studied the time taken for the return request which a consumer generated for the defective products running in warranty period. We feel that, if we combine Blockchain and BDA with RL, we can solve most of the existing problems and hence we have suggested few solutions based on Blockchain and Big Data Analytics.

\section{RESEARCH METHODOLOGY}

After going through a lot of research papers and text available online, we decided to conduct a questionnairebased survey and statistical analysis to achieve the objectives of our research paper. Our aim was to cover as many pin codes of India as possible and thus, get a clearer picture of the reverse logistics scenario on the e-commerce platforms. Survey which was asked to the consumers contained questions related to how often they return and the time taken for the pickup of the return/exchange order from the e-commerce company or the manufacturer, in case of return during warranty period. We also asked the time taken for receiving the product under secondary logistics. Few close-ended questions related to diversity, the type of purchase, from where they purchase and how much satisfied they are with the current situation of the return pickup were also included in the questionnaire.

The questionnaire was designed to achieve the following objectives:

- Understanding the total number of days required to arrange pick-up of a product

- Understanding the total number of days required to get the replaced product

- Understanding the quality of service provided by ecommerce companies in different cities. (Later on, we segregated the cities tier-wise)

- Understanding the major reason of returns

We received total of 566 responses from our survey, out of which 32 responses were incomplete and hence were removed from the data set. Out of 534 responses, 112 respondents said that they have never returned or exchanged any product. We removed these 112 respondents to get an accurate dataset of 422 respondents for the analysis. Tableau 2020.2 was used for the data visualization.

\section{SURVEY ANALYSIS AND RESULTS}

Responses of the 422 respondents were segregated into different tiers based on the pin codes which they provided in the survey. Segregation into different tiers was based on the data from the HRD ministry of the government of India (Financial Express, 2017). We were able to get responses from 123 cities, 21 states and 3 Union Territories. In [Figure $1]$, we have shown the density of pin codes on the map of India that we touched Pan-India, including regions from all over the country. 


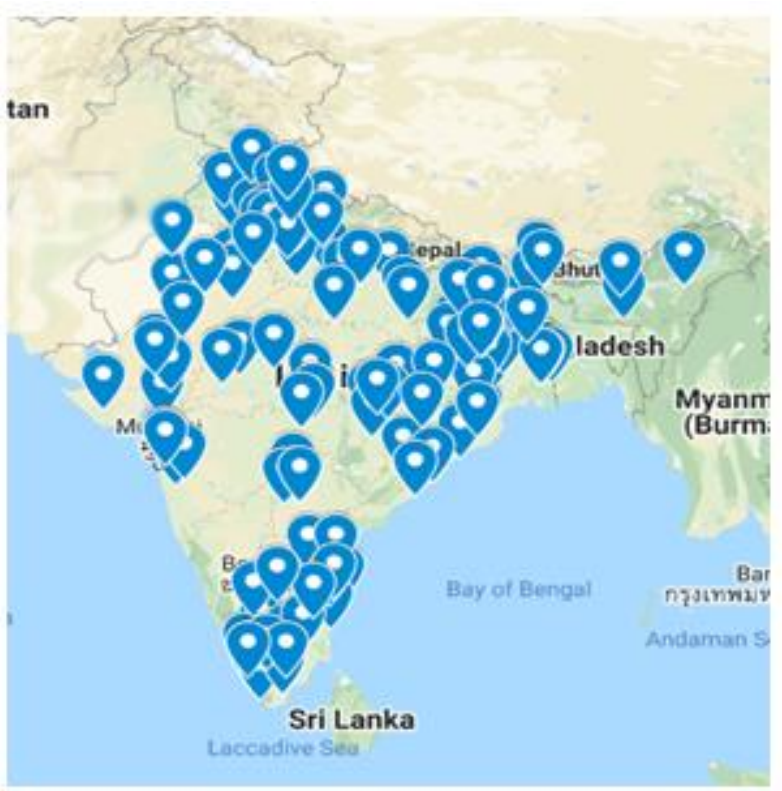

Figure 1

The results of this survey were very interesting and are discussed below:

A total of $78.78 \%$ people who shop online, return a minimum of $20 \%$ ( 1 out of 5 products) of the products that they purchase. Refer [Figure 2]

Majority of the consumers (53.08\%) that shop online are between the age of 25 years and 34 years, closely followed by the consumers between 15 years and 24 years, which makes up to $39.34 \%$ of the total consumer base. If we add them both, we find that $91.01 \%$ of the total consumers

\section{R/E Percentage}

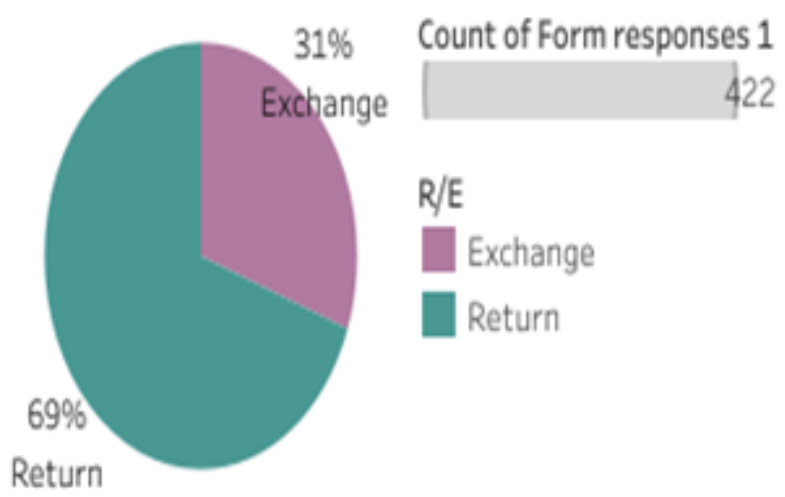

Figure 3

\section{A. Pickup Time and Satisfaction Analysis}

From our data set of 422 respondents, we analyzed the satisfaction of the respondents based on the pickup time of the return request. The analysis was performed Tier wise. Satisfaction index was measured on the likeability scale; where 1 meant very unhappy and 5 was very happy. For our analysis, we used clubbed 1, 2 and 3 as not satisfied

\section{Rate of Return}

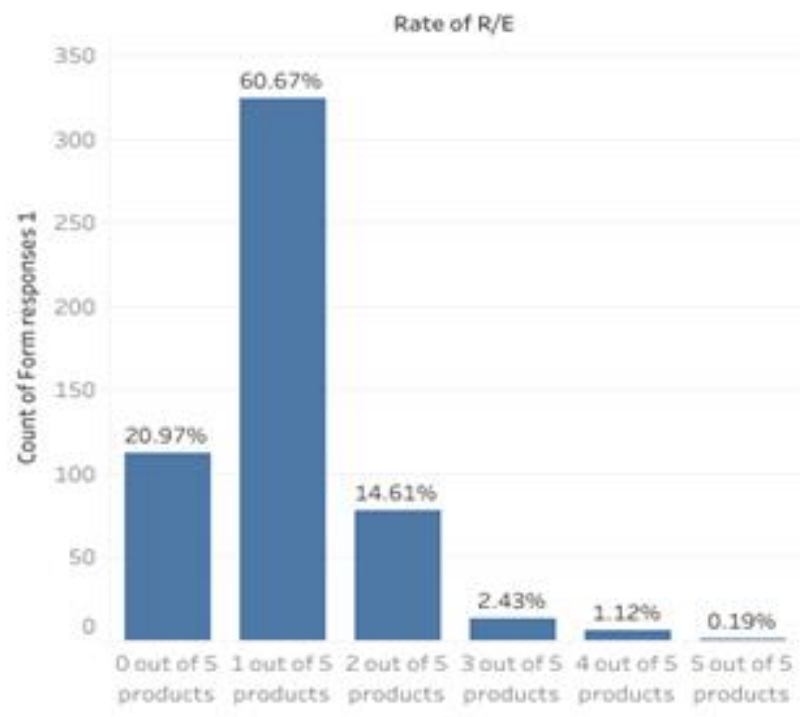

Figure 2

that shop online are less than 35 years of age. Refer [Figure 4]

Out of those $78.78 \%$ people who return, $31 \%$ choose the option of EXCHANGE while the other 69\% choose the option of RETURN. Refer [Figure 3]

Reasons of return were majorly categorized as damaged products, inferior quality, and wrong products. $37 \%$ consumers return because they received wrong product. For reasons like damage product and inferior quality, the percentage was as high as $59 \%$ and $62 \%$ respectively.

\section{Age Analysis}

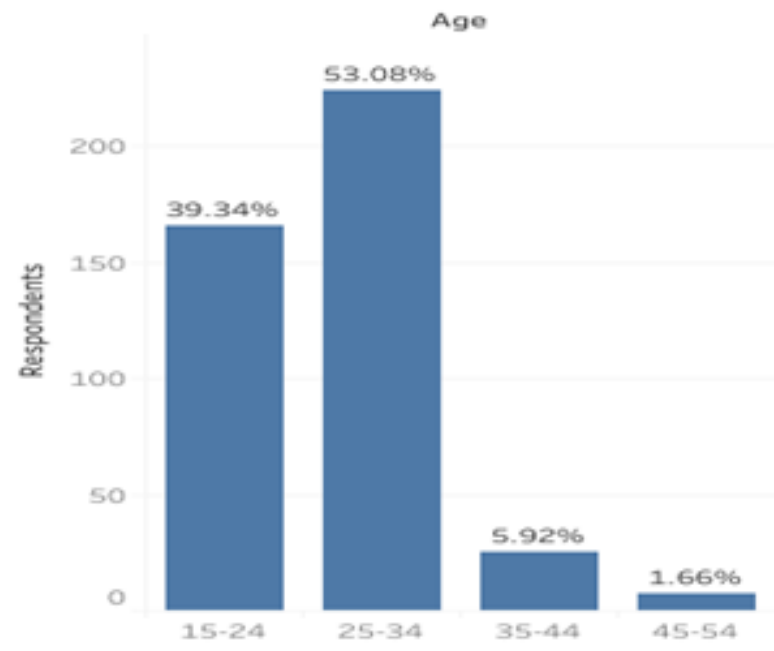

Figure 4

consumers, 4 as satisfied and 5 as very satisfied consumers. To have an in-depth analysis of the survey results, we segmented the cities into different Tiers. The analyses of different Tiers are as follows:

Published By:

Blue Eyes Intelligence Engineering

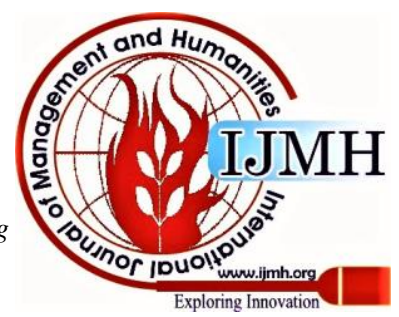


Tier1:

There where total of 110 respondents from Tier 1 cities. Out of them, $42 \%$ said that, they receive the pickup order in $1-2$ days for the return on e-commerce platforms and only 32\% said that, they receive the pickup order in 1-2 days for products running in warranty period. Tier 1 city, which should set a benchmark in the field of logistics, is lagging behind as the average satisfaction of the respondents is just 3.6. Satisfaction of the respondents from Tier 1 cities is shown in [Figure 5]. We can see that, there is a lot of scope of improvement in Tier 1 cities as consumers expects to receive the pickup in 1-2 days.

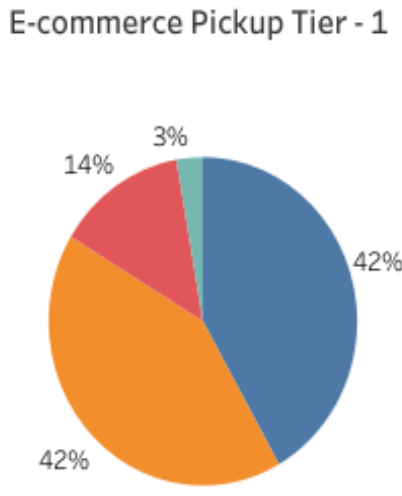

E-commerce Pickup Vs Satisfaction (Tier 1)

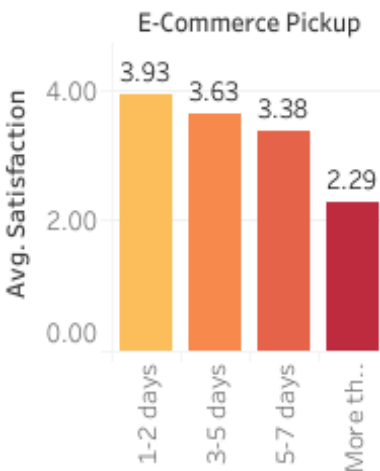

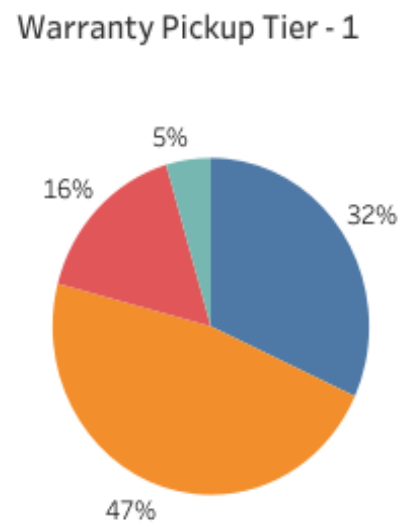

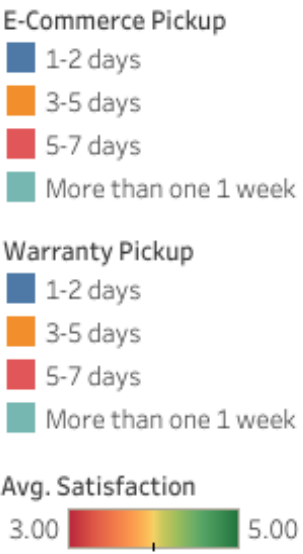

Tier2:

There where total of 195 respondents from Tier 2 cities. Out of them, $35 \%$ said that, they receive the pickup order in 1-2 days for the return on e-commerce platforms and only $28 \%$ said that, they receive the pickup order in 1-2 days for products running in warranty period. In Tier-2

\section{E-commerce Pickup Tier-2 E-commerce Pickup Vs Satisfaction (Tier 2)}
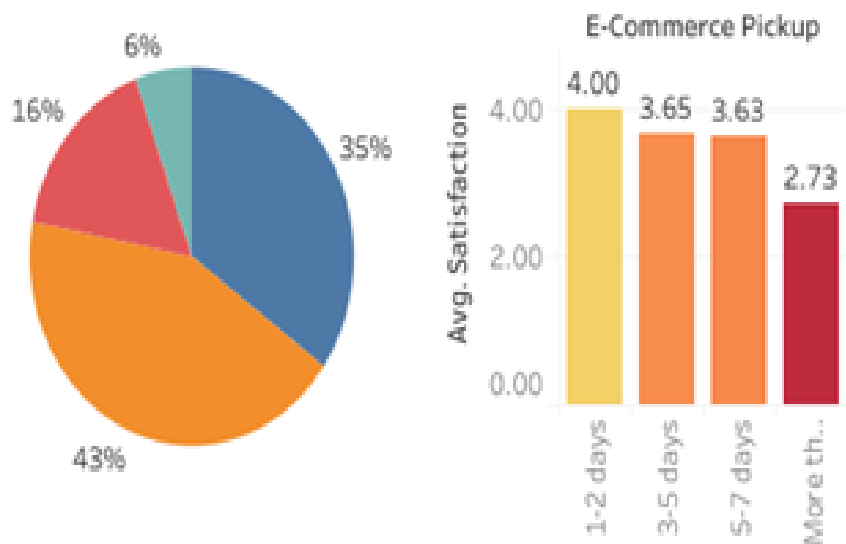

city, only $30 \%$ of the respondents are satisfied and the average satisfaction of the respondents is just 3.7. Satisfaction of the respondents from Tier 2 cities is shown in [Figure 6].
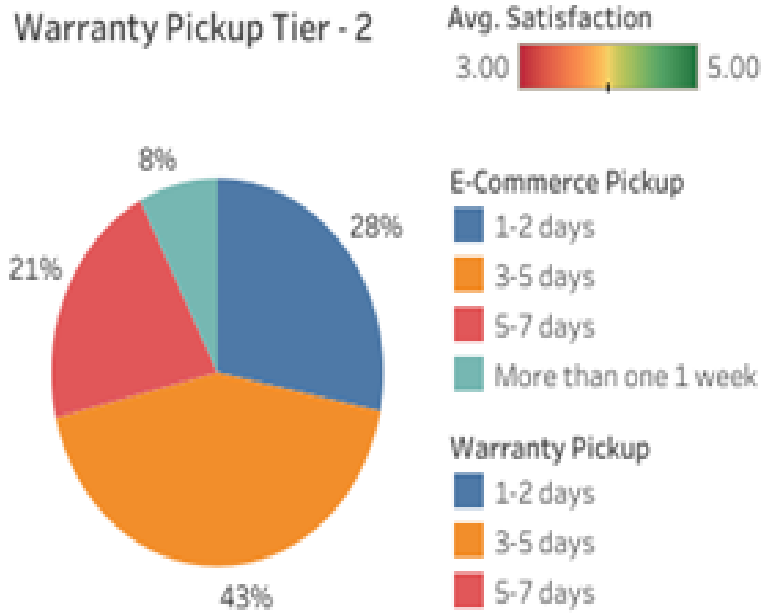

Figure 6

Tier3:

There were total of 117 respondents from Tier 3 cities. Out of them, $34 \%$ said that, they receive the pickup order in 1-2 days for the return on e-commerce platforms and only $22 \%$ said that, they receive the pickup order in 1-2 days for products running in warranty period. Survey analysis on the satisfaction of the respondents of Tier 3 cities was almost similar to the respondents of Tier 2 cities. The average satisfaction of the respondents is 3.6. Refer [Figure 7] for details.

- We can conclude following points from the analysis of the pickup point and satisfaction:

- Irrespective of the tier, it takes more time to pick up the return request order for the products running in warranty period. It shows that manufacturing companies are not well equipped to carry out the process of reverse logistics.

- We cannot benchmark Tier 1 cities as the average satisfaction remains almost same in all the Tiers.

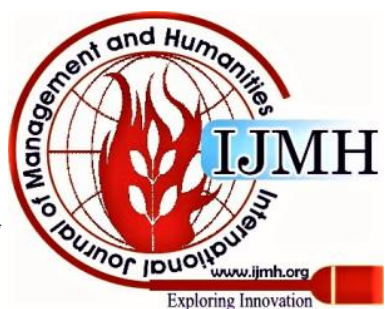




\section{Reverse logistics of Indian E-Commerce Industry- Consumer Perspective and Ways to Improve}

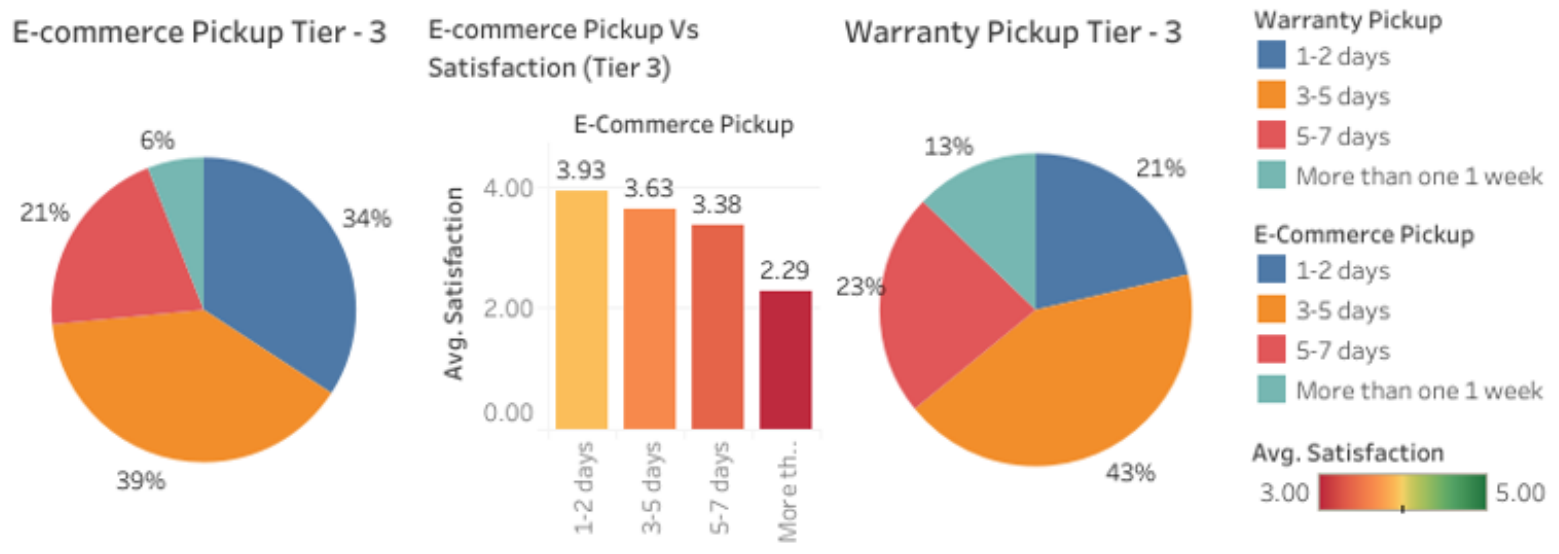

Figure 7

Analysis of the time taken to receive the replaced products To fulfill the objective of our study, we segregated this analysis into two platforms i.e. e-commerce and manufacturer. E-commerce platforms deal with the product which was sent to them and manufacturer deals with the return products running in warranty period.

E-comm Replaced Prod Tier - 1

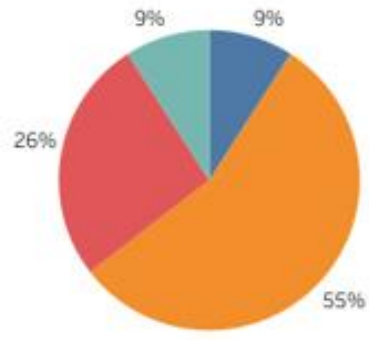

E-comm Replaced Prod Tier - 2

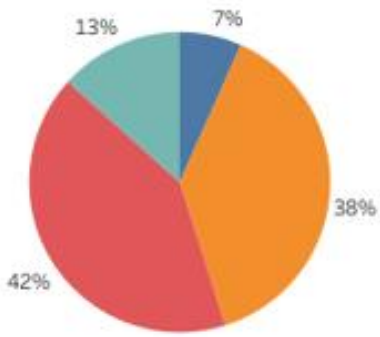

\section{B. E-commerce Platform}

In Tier 1 cities, $35 \%$ respondents said that it takes more than 5 days to receive the replaced products [Figure 8]. In Tier 2 and Tier 3 cities, it was 57\% and 63\% respectively

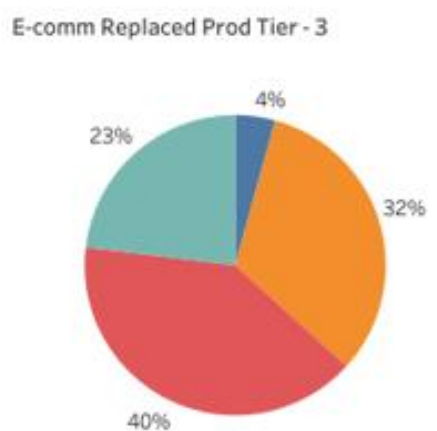

Figure 8

\section{Manufacturer Platform}

In Tier 1 cities, $63 \%$ respondents said that it takes more than 5 days to receive the replaced products [Figure 9]. In Tier 2 and Tier 3 cities, it was $61 \%$ and 64\% respectively.
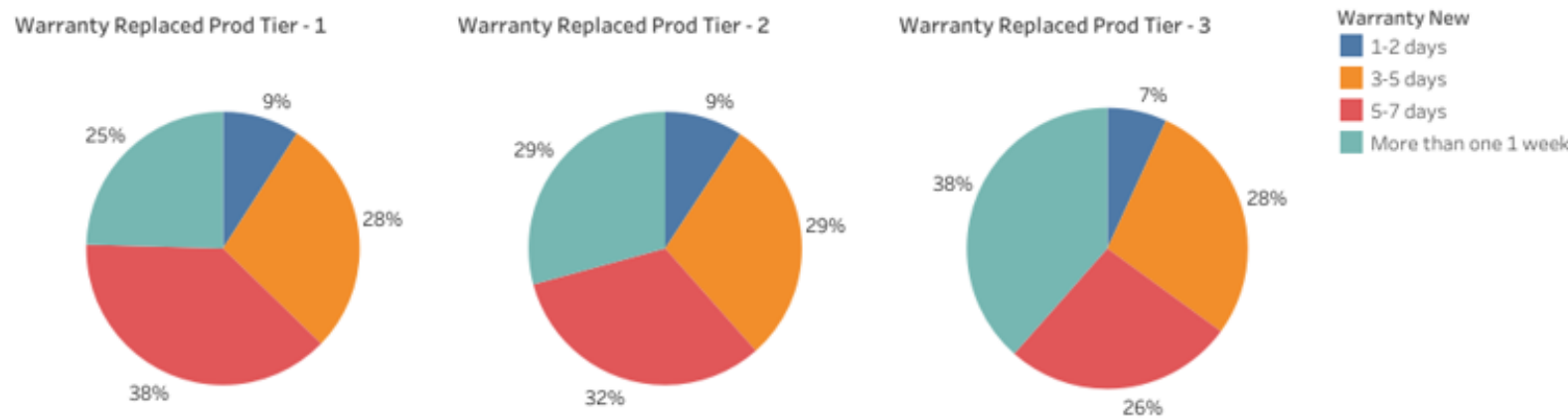

Figure 9

We can conclude following points from the analysis of the time taken to receive the replaced products:

- Providing the replace product is a cumbersome process as it requires many scrutiny and logistics

- Manufacturing companies should find measures to provide a quick service for the products replaced, running in the warranty period, due to defects.

- E-commerce Company's service to provide the replaced products in Tier 2 and Tier 3 cities is not efficient.

\section{Analysis of Reason and Rate of Return}

As said above, there are $78.78 \%$ people who return at least $20 \%$ of products purchased online. Reasons of returns were majorly categorized as damage products, inferior quality, and wrong product. $39 \%$ people return because they receive wrong product. For damage product and inferior quality categories, the percentage was as high as $60 \%$.

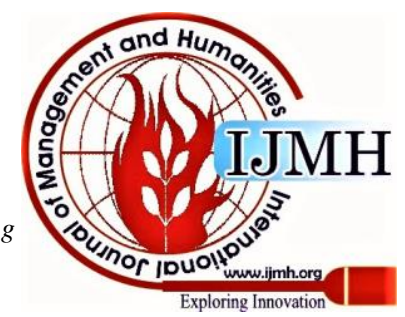


We can conclude following points from the analysis of the reason and rate of return:

- Conveyance has to be improved while shipping the product to the consumer

- $\quad$ Returns due to receiving the wrong products or inferior quality products, clearly shows, the inefficiency in the operational functions of the E-commerce companies.

Damage Products

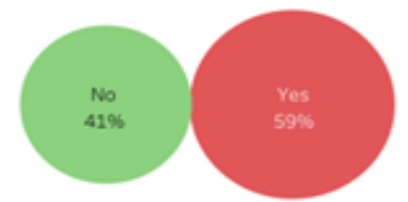

Inferior Products

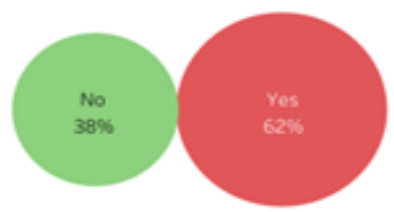

Wrong Products

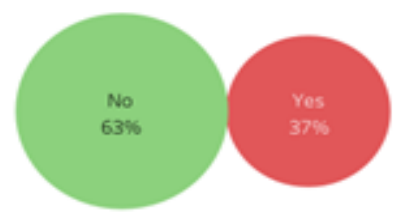

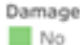

늘

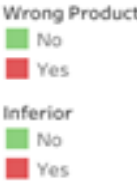

Figure 10

\section{DISCUSSIONS}

In our survey, we asked respondents to share their bad experience related to return or exchange of the products. Major Issues which was reported by the respondents from the Tier 1 cities were related to the inferior quality \& defective products, delay in receiving replaced products inconvenience in accepting the return request and delay in refund. After doing further analysis, we found that, these issues were common among all the Tiers. Few other major issues which were reported by the respondents from the Tier 2 cities were companies were not supportive enough to process the return request, fake products were delivered, replaced products were also defective and consumers were asked to courier the damaged product to the manufacturer. After analyzing the results of the survey and these bad experiences we are proposing following measures, which if implied, could be used to resolve most of the problems.

\section{A. Implementation of Big Data Analytics}

We are suggesting following measures based on Big Data Analytics, which can solve few of the problems related with reverse logistics:

By analyzing the trend of the consumer behavior related to the purchase of the product from the e-commerce companies, these companies can figure out the time period when they face maximum number of returns. Accordingly, they can tell their logistics partner to be prepared with the extra workforce. By analyzing the individual consumer behavior, they can find out the chances of return of the product from the respective consumer.

By using Big Data Analytics and blockchain we can track the vehicle routing. We can have the live updates of the vehicles that will be crossing the warehouse of the logistics company, can pick up the order and deliver it to the destination. This will be very useful when the logistics company receives an order when its last vehicle has moved or in case its vehicle is out of service.

As also suggested by DHL in its white paper, we can use big data to implement crowd-based deliveries and pickup. Applied to a distribution network, a crowd-based approach may create substantial efficiency enhancements on the last mile. The idea is simple: Commuters, taxi drivers, or students can be paid to take over last-mile delivery on the routes that they are travelling anyway. Scaling up the number of these affiliates to a large crowd of occasional carriers effectively takes load off the delivery fleet. (DHL, 2013)

\section{B. Implementation of Blockchain}

Blockchain is a distributed public consensus system that maintains an immutable record of transactions on the web, incapable of being falsified after the event. The distributed nature of the platform allows for greater oversight and control of the products while real time tracking via smart contracts give supply chain stakeholders the flexibility to make rapid decisions and update inventory levels on a continuous basis thereby reducing working capital inactivity. Leveraging blockchain, digital identities have been created for all the physical goods involved in the supply chain such as suppliers, manufacturers, distributors etc. The immutable nature of the blockchain enables us to record the complete chain of custody for every item that is logged on the blockchain from their origin to the point of sales. We are suggesting following three measures based on blockchain, which can solve few of the problems related with reverse logistics:

- In order to improve the pickup time, we can link the ecommerce body, retailer, consumer, manufacturer, and third-party Logistics Company that will facilitate the pickup. As soon as the consumer places the return request, it will be visible to all. Retailer or the ecommerce company can check and give the approval of the acceptance of return to the logistics company, who in turn, can notify one of its employees who is in the vicinity of the consumer. This will fasten the process of return pickup. It will also increase the transparency and will solve all the issues related to not accepting the return order.

Published By:

Blue Eyes Intelligence Engineering \& Sciences Publication (C) Copyright: All rights reserved.

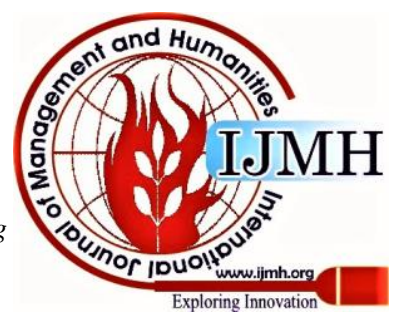


Using this method, retailer has to give reason for not accepting the return and the reason should be based on the basis of a smart contract.

- Blockchain can also solve the issues related to the refund of the money to the consumer if they return the product. Blockchain is equipped with the feature of smart contract which enables both the parties to do the business as per set of contracts which is highly encrypted. Digital signatures will be used to get the confirmation from both the parties. As per this feature, consumer has to keep the money on the blockchain platform. If the consumer receives the product as per smart contract, the money will be transferred to the retailer account after the consumer's approval. If he rejects the product, then the consumer has to specify which part of the smart contract was violated.

This will help both Retailer and the consumer. Retailers won't have to face fake return request.

- Many respondents said that, they return the product because they receive wrong products. Major segment of the wrong products was from the electronics segment. This might be because of the increased vulnerability of these items to thefts. Blockchain can be used to solve the problem. As mentioned earlier, we can interlink manufacturer, e-commerce platform and the consumer. While manufacturing a product, the manufacturer will add a unique code in the device, where the UI of the device will ask for the product key. Unless we enter the correct product key, device won't unlock. This product key will be shared with the e-commerce company who in turn will share it with the consumer by verifying his KYC details. When a consumer will place an order to buy the product, e-commerce Company will ask for their KYC details and then place the order. Once the order is received by the consumer, he has to send a message to the e-commerce company for the product key. After receiving the product key request, ecommerce Company will verify the KYC details with the consumer. If the detail matches, company will send the product key to the consumer. If we implement this, there won't be any loss of the product while in transit because no one can open the product without the product key.

\section{CONCLUSION}

Based on our study, there is a huge scope of improvement in the reverse logistics of e-commerce. Since there is close to $80 \%$ of the end-consumers who are returning at least $20 \%$ of the products purchased by them, and majority of them are returning due to the reasons that fall under the category of mismanagement in the forward logistics. Thus, if we are able to downsize the proportion of returns by optimizing our forward deliveries, it will also help in improving our reverse logistics since it will reduce the number of pick-ups and thus, improve the efficiency. This can be improved as soon as we integrate our forward and reverse logistics. Blockchain and Big Data Analytics will help us in solving most of the problem related to the reverse logistics. By using these techniques, we can solve many issues related to logistics and thus it will help to increase the customer satisfaction.

Moreover, we see that there is a huge lag in the services provided to the consumers of tier- 1 cities against the services provided to the consumers from tier- 2 and tier- 3 cities. This can be efficiently managed by using modern day techniques such as big data and blockchain; along with the modern- day solutions like crowd-based pick-ups and deliveries, and real time route optimization.

\section{LIMITATIONS}

"Research is formalized curiosity. It is poking and prying with a purpose"- Zora Neale Hurston. Every research has a purpose and a specific interest in mind. Our research paper has a purpose of improving the e-commerce reverse logistics of the Indian market. This paper has the following

limitations:

- The survey data is exclusive to the Indian consumers and thus, this study should not be expanded to the demography outside India.

- Majority of the suggestions provided by us are based on a theoretical approach after studying more than 60 research papers, more than 25 white papers and uncountable website articles. They are subject to market study and implementation that follows.

\section{REFERENCES}

1. The Top 20 Economies in the World. (2020). Investopedia. https://www.investopedia.com/insights/worlds-top-economies/

2. P. (2018, January 29). India's logistics sector to reach USD 215 bn by 2020: Survey. The Economic Times. https://economictimes.indiatimes.com/industry/transportation/shippin g-/-transport/indias-+logistics-sector-to-reach-usd-215-bn-by-2020survey/articleshow/62693817.cms?from $=\mathrm{mdr}$

3. Www.Investindia.Gov.In. https://www.investindia.gov.in/team-indiablogs/reverse-logistics-gaining-traction-india

4. Correspondent, S. (2019, June 27). Cut logistics cost to 9\% of GDP, Goyal tells $\quad$ States. The Hindu. https://www.thehindu.com/business/cut-logistics-cost-to-9-of-gdpgoyal-tells-states/article28191323.ece

5. Saleh, K. (2018, April 11). E-commerce Product Return Rate Statistics and Trends [Infographic]. Invesp. https://www.invespcro.com/blog/ecommerce-product-return-ratestatistics/

6. Rogers, D. S., Tibben-Lembke, R. S., \& University of Nevada, Reno. C. for L. M. (1999). Going Backwards. Reverse Logistics Executive Council.

7. Adlmaier, D., \& Sellitto, M. A. (2007). Embalagens retornáveis para transporte de bens manufaturados: um estudo de caso em logística reversa. Production, 17(2), 395-406. https://doi.org/10.1590/s010365132007000200014

8. Fen, M. (2010). The Study of Reverse Logistics for Ecommerce. IEEE, 1(2010), https://doi.org/10.1109/ICMSS.2010.5575577

9. Meng, M. H., \& Qian, Y. (2018). The Blockchain Application in Supply Chain Management: Opportunities, Challenges and Outlook. Research Gate, November (1), 1. https://doi.org/10.29007/cvlj

10. Crosby, M., Pattanayak, P., Verma, S., et al.: Blockchain technology: beyond bitcoin. Appl. Innov. 2, 6-10 (2016)

11. De Mauro, A., Greco, M., \& Grimaldi, M. (2016). A formal definition of Big Data based on its essential features. Library Review, 65(3), 122-135. https://doi.org/10.1108/lr-06-2015-0061

12. Nguyen, T., ZHOU, L., Spiegler, V., Ieromonachou, P., \& Lin, Y. (2018b). Big data analytics in supply chain management: A state-ofthe-art literature review. Computers \& Operations Research, 98, 254 264. https://doi.org/10.1016/j.cor.2017.07.004

Blue Eyes Intelligence Engineering \& Sciences Publication (C) Copyright: All rights reserved. and

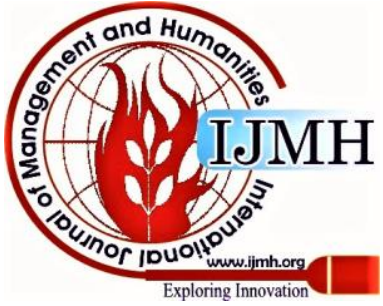


13. Goyal, Nitika \& Goyal, Deepam. (2016). Impact of E-Commerce in India: Issues \& Challenges. International Journal of Advanced Research in Computer Science. 7. 192-194.

14. KPMG. (2018, May). E-Commerce Retail Logistics in India https://assets.kpmg/content/dam/kpmg/in/pdf/2018/05/e-commerceretail-logistics.pdf

15. Prakash, C., Barua, M. K., \& Pandya, K. V. (2015). Barriers Analysis for Reverse Logistics Implementation in Indian Electronics Industry using Fuzzy Analytic Hierarchy Process. Procedia - Social and Behavioral Sciences, 189, 91-102. https://doi.org/10.1016/i.sbspro.2015.03.203

16. Saurabh Agarwal. (2018, June). Reverse Supply chain (RSC) Issues in Indian electronics industry. www.econstor.eu. https://www.econstor.eu/bitstream/10419/195121/1/1032371293.pdf

17. S. Olaf, "Reverse Logistics", John Gattorna (edi), Gower Handbook of Supply Chain Management, Gower Publishing, Aldershot: 2003, pp.267-279.

18. Deloitte. (2017). When Supply chain meets Blockchain https://www.deloitte.com

19. Zhu, Q., \& Kouhizadeh, M. (2019). Blockchain Technology, Supply Chain Information, and Strategic Product Deletion Management. IEEE Engineering Management Review, 47(1), 36-44. https://doi.org/10.1109/emr.2019.2898178

20. Wu, H., Cao, J., Yang, Y., Tung, C. L., Jiang, S., Tang, B., Liu, Y. Wang, X., \& Deng, Y. (2019). Data Management in Supply Chain Using Blockchain: Challenges and a Case Study. 2019 28th International Conference on Computer Communication and Networks (ICCCN), 1. https://doi.org/10.1109/icccn.2019.8846964

21. Rožman, N., Vrabič, R., Corn, M., Požrl, T., \& Diaci, J. (2019). Distributed logistics platform based on Blockchain and IoT. Procedia CIRP, 81, 826-831. https://doi.org/10.1016/j.procir.2019.03.207

22. DHL. (2013, December). Big Data in Logistics. https://www.dhl.com/content/dam/downloads/g0/about_us/innovation /CSI_Studie_BIG_DATA.pdf

23. Apte, S., \& Petrovsky, N. (2016). Will blockchain technology revolutionize excipient supply chain management? Journal of Excipients and Food Chemicals, 7(3), 76-78. [910]. https://jefc.scholasticahq.com/article/910

24. P., D., \& Ahmed, K. (2016). A Survey on Big Data Analytics: Challenges, Open Research Issues and Tools. International Journal of Advanced Computer Science and Applications, 7(2), 511-518. https://doi.org/10.14569/ijacsa.2016.070267

25. Ma, J., Kwak, M., \& Kim, H. M. (2014). Demand Trend Mining for Predictive Life Cycle Design. Journal of Cleaner Production, 68, 189-199. https://doi.org/10.1016/j.jclepro.2014.01.026

26. Online, F. E. (2017, July 12). 7th Pay Commission: Check your city category here and the amount of HRA you will get in August salary. The Financial Express. https://www.financialexpress.com/money/7thpay-commission-hra-allowances-check-your-city-category-here-andthe-amount-of-hra-you-will-get-in-august-salary/760809/

\section{AUTHORS PROFILE}

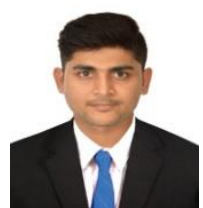

Avinash, is zestful person with deep interest in operations and data science. He graduated as a mechanical engineer from BIT Sindri in 2017.Post his graduation, he worked with L\&T in their R\&D sector. $\mathrm{He}$ is a data centric person and likes to analyse data and bring the key visualization from it. He believes that an effective use of Blockchain and Big Data Analytics can optimize and solve key problems of most of the industries. Scope of data science is humongous but we need to find out the ways through which we can implement these techniques to increase the customer satisfaction.

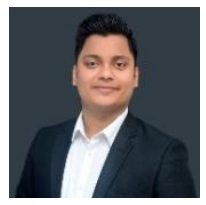

Neeraj, is a dynamic person with deep interest in the supply chain industry. He worked for one of the biggest logistics companies of the world. He graduated as a mechanical engineer in 2018 and since then, he is directly or indirectly associated with many supply chain professionals around the world. He plans to improve the Indian supply chain and wants to work in this domain even after the completion of his post-graduation. Neeraj believes that the use of technology and automation can bring exponential changes in the supply chain industry and wants to continue his work in this direction. He is a visionary in true sense

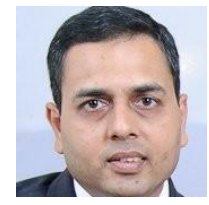

Rajesh Kumar, a professional with a passionate blend of Marketing and Technology skills which places him in a unique position to both leverage Digital and offline marketing effectively. He has worked on both a client and as a service provider, which makes him an experience enriched professional. He has done his under graduation in mechanical engineering and later on pursued MBA from IMT Ghaziabad. He has worked with corporates like Hinduja Tech. Because of his keen inclination towards academics, he pursued a doctorate degree in marketing from DoMS, IIT Chennai. Currently, he is working as an associate professor with IFIM Bengaluru and is very passionate about helping students in their research work. 